\title{
The Influence of Industrial Industry Structure Change on Chinese Education Structure
}

\author{
Jiajia Yu,Jing LI, LishanXiong, Yuqi Han",Lin Fan, Dan Luo \\ Chongqing Jianzhu College, Chongqing, China \\ *Corresponding Author.
}

\begin{abstract}
With the continuous development of economic globalization, changes in the industrial structure have become an indispensable material basis in the current process of social and economic changes. Optimize and develop the internal structure of each industry, especially industrial industry, and use the functional expansion of the industrial structure as a transformation model to promote the educational structure, thereby realizing the upgrading of the economic development industry.
\end{abstract}

Keywords: Industrial industry, structure, education structure

\section{I.Introduction}

With the continuous deepening of economic theory in national education, industrial structure as one of the necessary means of economic development, it is of great necessity to study it, especially for China's educational structure, has broad development prospects. However, due to the continuous development of the economy and the continuous changes in education, the development of all walks of life is unbalanced and unstable. This paper studies the impact of industrial structure changes on the education structure under the new normal. By constructing a model of the influence of industrial structure on the structure of my country's education structure, we can find out how to coordinate the industrial structure and education structure of economic development.

According to the industrial structure and the national economic tax situation, Si Ping takes Ningxia as a case city and uses the new basic factor analysis method to calculate the tax structure and its internal industrial adjustment. Finally, according to the industrial structure and the national economic tax situation, the author makes an economic calculation on the tax structure and its internal industrial adjustment a series of proposals [1] have been made for the existing problems. In the research on the adjustment and optimization of industrial structure in the context of the new normal of economy, Yang Hongrui. Combined with the basic performance normality of employment structural contradiction and the internal contradiction of various industrial structure modes, analyzed the development breakthrough of education structure on the basis of high-end and low-end industries and talent resources at all levels, and finally realized the change of internal industrial structure [2]. Wang Hui has formulated the target tasks of developing the current economy and promoting employment growth. Through the analysis of various types of industrial characteristics and modes, the basic measures for industrial structure adjustment have been put forward [3].

\section{II.Industrial Structure Changes under the New Economic Normal}

The Chinese new economic normal is the symmetry of the economic structure. Economic sustainable development based on the symmetry of the economic structure includes sustainable and stable economic growth. The new economic normal is an economy that adjusts the structure of stable growth, not a total economy; it focuses on the symmetry of the economic structure and sustainable development on the basis of the symmetry, not just GDP, GDPgrowth per capita, and economic scale maximization[4]. The new normal of the economy is to use growth to promote development and development to promote growth. Industrial structure refers to the proportion of agriculture, industry and service industries in a country's economic structure. On the one hand, changes in the 
industrial structure have brought good market opportunities to certain industries, and on the other hand, they have also threatened the survival of other industries. The change of industrial structure under the new normal state refers to abandoning the inherent model, learning from each other, optimizing and establishing a new industrial structure under the old economic industrial model, and optimizing and upgrading the system status itself to promote the society to enter a new development stage and optimization direction.

The more general industrial structure classification method in the world is to divide the industrial structure according to the historical development order of social production activities. The sector where products are taken directly from nature is called the primary industry, the sector that reprocesses primary products is called the secondary industry, and the sector that provides various services for production and consumption is called the tertiary industry. The primary industry refers to the traditional agriculture and mining industries. The secondary industry refers to the manufacturing industry. The tertiary industry refers to the service industry, including leisure, entertainment, tourism and other industries. Industrial structure division is an important step in industrial structure transformation. Through the division and distribution of industrial structure, we can see the current status of social and economic development and the direction of optimization. Since the reform and opening up, Chinese industrial structure has changed as shown below (Figure 1).

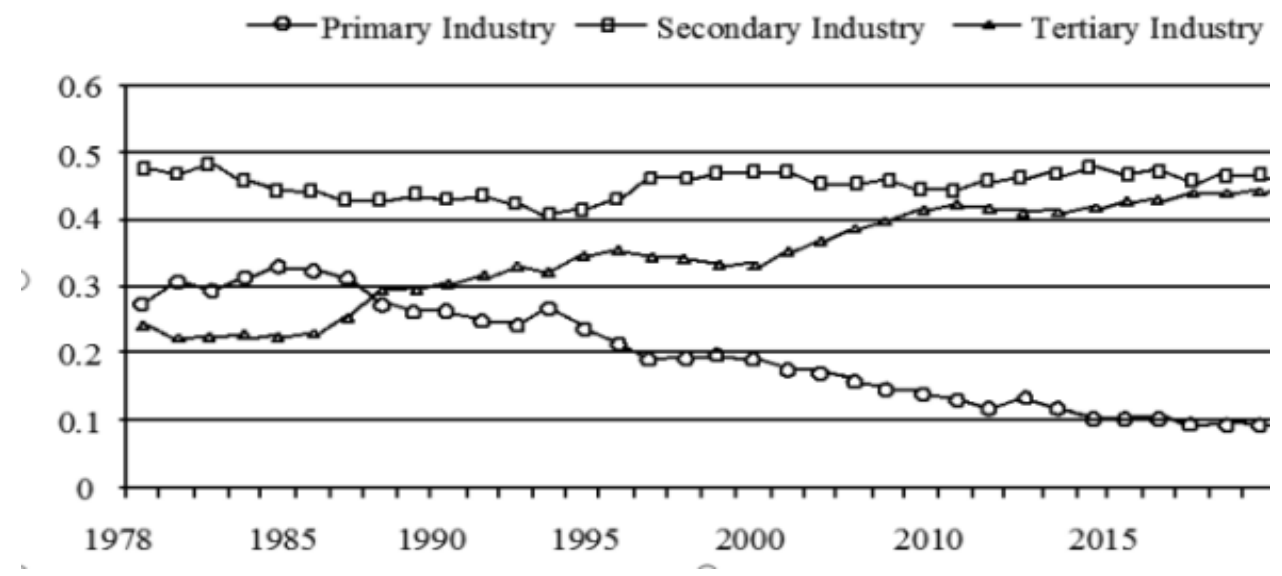

Fig 1: Changes in the proportion of Chinese three major industries in GDP

It can be seen from the figure that the basic trend of the first industry is from fluctuation to decline, the second industry is always in a high level of small fluctuations, and the third industry is in a rising trend. The basic structure of the three basic industries fluctuates up and down. There is no intersection between the primary and secondary industries, but the tertiary industry intersects with the primary and secondary industries respectively. The intersection with the primary industry is basically in 1985 between 1990 and 1990, the primary industry was developing rapidly, and the tertiary industry was inspired; the meeting point with the secondary industry was basically between 2015-2016. In the past 19 years, with the rapid development of the tertiary industry, the development of the tertiary industry has gradually become the largest and most popular industrial cluster.

Therefore, with the continuous adjustment, optimization and upgrading of the industrial structure, a structural economic development model system with primary industries as the primary to tertiary industries has been initially formed, which has also affected the changes in the educational structure.

\section{III.Construction of Chinese Educational Structure Model}

In China, education is divided into kindergarten, elementary school, junior high school, high school, university and other forms of education. According to the economic growth analysis model, Cobb-Douglas production function: 


$$
Y=A F(L, K)=A(\mathrm{t}) L^{\alpha} K^{\beta}(1)
$$

Among them, Y represents the GDP of economic growth, L represents the labor force, $\mathrm{K}$ represents the capital stock; $\mathrm{A}(\mathrm{t})$ represents the level of technological progress; $\alpha, \beta$, and $\mathrm{t}$ are the output elasticity coefficients of the labor factor, capital factor, and technology factor, respectively. If the gross domestic product of each industry replaces the gross domestic product labor represented by employees and wages, the value-added function formula of each industry is as follows:

$$
Y^{t}{ }_{N}=A^{t}{ }_{N}\left(K^{t}{ }_{N}\right) a^{t}{ }_{N}\left(L^{t}{ }_{N}\right) \beta^{t}{ }_{N}
$$

The wage level of each industry in the period ${ }^{t}$ is:

$$
w^{t}{ }_{N}=\frac{\partial Y^{t}{ }_{N}}{\partial L_{N}^{t}}=\frac{\partial A^{t}{ }_{N}\left(K^{t}{ }_{N}\right)^{\alpha^{t}}\left(L_{N}^{t}\right)^{\beta^{t}{ }_{N}}}{\partial L_{N}^{t}}=\frac{\beta^{t}{ }_{N} Y^{t}{ }_{N}}{L_{N}^{t}}
$$

In the formulas, $Y_{1}^{t} 、 Y_{2}^{t} \cdots Y_{N}^{t}$ represents the added value of each industry in the period $t, L_{1}^{t} 、 L_{2}^{t} \cdots L_{N}^{t}$ represents the total number of employees in each industry in the period $t, K^{t}{ }_{1} K^{t}{ }_{2} \cdots K^{t}{ }_{N}$ represents the total capital of each industry in the period $t, w_{1}^{t} 、 w_{2}^{t} \cdots w_{N}^{t}$ represents the wage level of each industry in the period, $A^{t}{ }_{N}$ represents the technical level of each industry in the period $t$.

Then suppose that the total number of education subjects is $M$, and the proportion of graduates in a certain academic year in the total number of graduates is $G_{i}^{t} . G_{i}{ }_{i}$ is divided into industry average wage proportion variable $S^{t}{ }_{i}$ and constant vector $H^{t}{ }_{i}$ caused by other index factors. The program is as follows:

$$
G^{t}{ }_{i}=S^{t}{ }_{i}+H^{t}{ }_{i}
$$

In this formula, $i$ represents a discipline in the total number of disciplines $M$, and $t$ also represents time period. Therefore, it can be seen that the larger the change of the average salary of the selected subject, the more the number of graduates in the academic year of the selected subject gradually increases, but the education structure under the constant vector will not change, and it is in the inertia state. On the other hand, the basic display proportion of the number of graduates is also affected by the total number of people in different industries and the level of wages in various industries. Finally, the basic scale state of the total number of education disciplines $M$ is formed.

Considering the change of the average wage of each industry, assuming that the number of graduates of each school changes with the average wage of the industry, once the motivation of discipline selection is determined, the average wage of the discipline is directly proportional to the total wage of the whole industry[5], as shown below:

$$
\begin{aligned}
& S_{i}^{t+n}=f\left(W_{i}^{t}-\stackrel{-}{W}^{t}\right) \\
& W_{i}^{t}=a_{i 1}^{t} w_{1}^{t}+a_{i 2}^{t} w_{2}^{t}+\ldots a_{i N}^{t} w_{N}^{t} \\
& \stackrel{+}{W}^{t}=b^{t}{ }_{m 1} w_{1}^{t}+b^{t}{ }_{m 2} w_{2}^{t}+\ldots+b^{t}{ }_{m N} w_{N}^{t}
\end{aligned}
$$


$W_{i}^{t}$ refers to the expected salary level of $\bar{W}^{t}$ discipline stage, $n$ refers to the average level of discipline after entering the specific education level, $b^{t}{ }_{m N}$ refers to the specific time of schooling after entering the education level, $N$ refers to the specific proportion of discipline entering the FF stage, and $N$ refers to the total number of industries. The optimal solution is obtained by substituting $S_{i}^{t+n}$ into the following formula.

$$
\left\{\begin{array}{l}
S_{i}^{t+n}=f\left[A_{1} w_{1}^{t}+A_{2} w_{2}^{t}+\ldots+A_{n} w_{N}^{t}\right] \\
A_{n}=a_{i N}^{t}-b_{m N}^{t}
\end{array}\right.
$$

In the formula, it can be concluded that the final value range of $b_{m 1}^{t}+b_{m 2}^{t}+\ldots+b_{m N}^{t}$ is 1 , so assuming that the period $t$ is a semester, $w$ is used as the domain range to calculate, and the function is as follows:

$$
S_{i}^{1+n}=f\left(A_{1} \frac{\beta_{1}^{1} Y_{1}^{1}}{L_{1}^{1}}+A_{2} \frac{\beta_{2}^{1} Y_{2}^{1}}{L_{2}^{1}}+\ldots+A_{n} \frac{\beta_{N}^{1} Y_{N}^{1}}{L_{N}^{1}}\right)
$$

If the unknown number $x$ is set to represent $S_{i}^{1+n}$ function, the linear basic model after staged feature display is as follows:

$$
S_{i}^{1+n}=b+k A_{1} \frac{\beta_{1}^{1} Y_{1}^{1}}{L_{1}^{1}}+k A_{2} \frac{\beta_{2}^{1} Y_{2}^{1}}{L_{2}^{1}}+\ldots+k A n \frac{\beta_{N}^{1} Y_{N}^{1}}{L_{N}^{1}}+\varepsilon
$$

In the above formula, taking $b, k$ as the basic variable coefficient, as the unknown number $x$ and $S_{i}^{1}$ present a positive proportion mode, we get $k>0$, and substitute it into $C n$ to get:

$$
\left\{\begin{array}{l}
C n=k \beta_{N}^{1}\left(a_{i N}^{t}-b_{m N}^{t}\right) \\
S_{i}^{1+n}=b+c_{1} \frac{Y_{1}^{1}}{L_{1}^{1}}+c_{2} \frac{Y_{2}^{1}}{L_{2}^{1}}+\ldots+c_{N} \frac{Y_{N}^{1}}{L_{N}^{1}}+\varepsilon
\end{array}\right.
$$

In the above formula, $i$ represents the discipline structure, $c$ represents four different parameters, including total number of industries, basic proportion of employment, equation construction parameter mode, and production program function. The total number of industries is $N$, the basic proportion of employment is $a_{i N}^{t}$, the parameter pattern of equation construction is $k$, and the function of production program is $\beta_{N}^{1}$.

On the basis of the basic measurement procedure, the change of the number of graduates in the education stage is calculated according to the difference of the wage level of each industry, and the final weighted function is calculated as follows:

$$
H_{i}^{t}=d H_{i}^{t-1}=d\left(G_{i}^{t-1}-S_{i}^{t-1}\right)
$$


In the formula, $d$ represents the weighted value range of the function, and after periodic calculation through the variable range of $i$ industry, it is found that the production function remains unchanged in a short period of time, and presents a dynamic model of $N=2$. The final equation model is shown as follows:

$$
G_{i}^{t}=b-d b+c_{1} \frac{Y_{1}^{t}}{L_{1}^{t}}+c_{2} \frac{Y_{2}^{t}}{L_{2}^{t}}=d G_{i}^{t-1}-d c_{1} \frac{Y_{1}^{t-1}}{L_{1}^{t-1}}-d c_{2} \frac{Y_{2}^{t-1}}{L_{2}^{t-1}}+\varepsilon
$$

If it is the second discipline, the basic model test after the minimum variance variable control is obtained after regression analysis, and finally the dynamic distribution lag co integration model of another discipline is calculated, which is expressed as the discipline relationship model of the second industry:

$$
G_{i}^{t}=b+k i \beta_{j}\left(a_{i N}^{t}-b_{m N}^{t}\right) \frac{Y_{j}^{t}}{L_{j}^{t}}+k i \beta_{-j}\left(b_{i N}^{t}-a_{m N}^{t}\right) \frac{Y_{-j}^{t}}{L_{-j}^{t}}
$$

This dynamic model has great data fit and adaptability for the program equation model of the first discipline, which is represented by the sum and distribution form of various variables. Finally, it is concluded that the development of each industry interacts with various graduation modes, average wages, education industry and other concrete relations of a discipline, and finally gradually becomes proportionally appropriate and structurally complete Basic function parameter model[6].

\section{IV.Empirical Analysis}

This article takes China as an example to study the impact of industrial structure changes on China's education structure under the new normal. Select the output value structure and employment data of China's three major industries from 2007 to 2016, and conduct empirical research based on the model. According to the model, the education structure is in the table(Table 1)

Table 1 Changes in the output structure and education employment structure of China's three industries

\begin{tabular}{|c|c|c|c|c|c|c|}
\hline \multirow{2}{*}{ Year } & \multicolumn{2}{|c|}{ Structure of Output $(\%)$} & \multicolumn{2}{c|}{ Structure of Employment for Education (\%) } \\
\cline { 2 - 7 } & $\begin{array}{c}\text { First } \\
\text { Industry }\end{array}$ & $\begin{array}{c}\text { Second } \\
\text { Industry }\end{array}$ & $\begin{array}{c}\text { Third } \\
\text { Industry }\end{array}$ & First Industry & Second Industry & Third Industry \\
\hline 2007 & 4.4 & 49.7 & 45.9 & 42.6 & 25.2 & 32.2 \\
\hline 2008 & 2.7 & 50.1 & 47.3 & 40.8 & 26.8 & 32.4 \\
\hline 2009 & 5.2 & 48.6 & 46.2 & 39.6 & 27.2 & 33.2 \\
\hline 2010 & 4.0 & 52.3 & 43.7 & 38.1 & 27.8 & 34.1 \\
\hline 2011 & 3.6 & 57.4 & 39.0 & 36.7 & 28.7 & 34.6 \\
\hline 2012 & 4.2 & 52.0 & 43.8 & 34.58 & 29.5 & 35.7 \\
\hline 2013 & 5.2 & 49.9 & 44.9 & 33.6 & 30.3 & 36.1 \\
\hline 2014 & 4.3 & 48.5 & 47.2 & 31.4 & 30.1 & 38.5 \\
\hline 2015 & 4.7 & 47.8 & 47.5 & 29.5 & 29.9 & 40.6 \\
\hline 2016 & 4.6 & 41.5 & 53.7 & 28.3 & 29.3 & 42.4 \\
\hline
\end{tabular}

Changes in the industrial structure have also led to corresponding changes in my country's education structure, which are manifested in the following aspects. First of all, the changes in the industrial structure have brought 
about a certain change in the society's demand structure for talents. The wage structure can be adjusted to further guide the changes in the number of graduates in different disciplines. The main training objective of educational institutions is to provide society with comprehensive talents to meet the employment needs of students. After a student graduates, the lower the employment risk, the more secure their employment. Therefore, students have different majors, and there are certain differences in their employment after graduation. The demand for talents in some majors is relatively large, and the salary is relatively high, so it will naturally attract more students. Therefore, changes in the industrial structure will cause a certain change in the demand for talents, and will also have a certain impact on the structure of educational institutions. Even changes in the industrial structure may cause some majors in the education industry to be cleared or new majors to be born. This also has an impact on the disciplinary structure of educational institutions. Secondly, the process of changing the industrial structure will be realized through some intermediate variables, so that certain macro variables such as interest rates and prices will undergo certain changes. This will also have a certain impact on students' employment choices and change the discipline structure of educational institutions. Students seek to maximize their personal interests, so they will make corresponding choices among the existing disciplines and majors. If a discipline can bring long-term benefits to the future, the number of students in the discipline will increase. Will decrease, which in turn will lead to changes in the educational structure.

\section{V.Conclusion}

Under the new economic normal, with the continuous optimization and adjustment of Chinese industrial structure, it will also bring about certain changes to its education structure. In this regard, Chinese education structure should fully understand the changing characteristics of the industrial structure and the needs of social talents, and take effective measures to promote the reform and improvement of its own education structure, so as to better cultivate application-oriented talents for the society and improve its own education. To promote the rapid development of our economy.

\section{Acknowledgements}

The study was supported by The Regulated Research Projects of National Education Science; Research on the impact of population structure change on educational investment and economic growth in China (EFA160401).

\section{References}

[1] P. Si, "Research on the impact of Ningxia's economic restructuring on tax revenue under the new normal,’Silk Road vision, vol. 2016, no. 7, pp. 10-11.

[2] H.R. Yang, J.N. Li, M. Tian, "Structural problems of employment in Hebei Province under the new normal and its implications for university employment," Journal of Hebei University of Geosciences, vol. 2015, no. 5, pp. 136-140.

[3] H. Wang, "On the Countermeasures of industrial structure adjustment under the new normal of economy," China Economic and trade guide, vol. 2015, no. 8, pp. 7-9.

[4] S.C. Sundararajan, S.V. Nitta, "Designing engaging intelligent tutoring systems in an age of cognitive computing,’Ibm Journal of Research and Development, vol. 59, no. 6, pp. 10:1-10:9, 2015.

[5] Y.Wang, "Inference Algebra (IA): A denotational mathematics for cognitive computing and machine reasoning (II)," International Journal of Cognitive Informatics and Natural Intelligence (IJCINI), vol. 5, no. 4, pp. 61-82, 2012.

[6] W.H. Chen, J.Y. An, R.F. Li,et al.,"Review on deep-learning-based cognitive computing," Acta Automatica Sinica, vol. 43, no. 11, pp. 1886-1897, 2017. 